\title{
Graphite-Supported Platinum Catalysts: Effects of Gas and Aqueous Phase Treatments
}

\author{
J. H. V leeming,* B. F. M. Kuster, ${ }^{*, 1}$ G. B. M arin,* F. O udet, $\uparrow$ and P. Courtine $\ddagger$ \\ *L aboratorium voor Chemische Technologie, Schuit Institute of Catalysis, E indhoven U niversity of Technology, P.O. B ox 513, 5600 M B E indhoven, \\ The N etherlands; †Service d' A nalyse P hysico-Chimique, U niversité de Technologie de Compiègne, Centre de R echerches de R oyallieu, \\ P.O. B ox 649, 60206 Compiègne C edex, France; and †D épartment de G énie Chimique, U niversité de Technologie de Compiègne, \\ Centre de Recherches de R oyallieu, P.O. B ox 649, 60206 Compiègne Cedex, France
}

R eceived September 19, 1995; revised September 16, 1996; accepted O ctober 14, 1996

The effects on the platinum particle diameter and the available platinum surface area of a graphite-supported platinum catalyst resulting from pretreatments and from performing a selective oxidation reaction are investigated. In the gas phase considerable catalyst sintering occurs only in the presence of oxygen at $773 \mathrm{~K}$ due to extensive carbon burn-off, whereas in an aqueous phase platinum particle growth is limited upon oxidative treatment. A hydrogen treatment in aqueous phase at $363 \mathrm{~K}$ causes platinum particle growth, aggregate formation, and covering of metal sites. These phenomena become more important with increasing $\mathrm{pH}$. Platinum particle growth and aggregate formation are attributed to platinum particle rather than platinum adatom mobility and is caused by the destruction of the oxygen-containing surface groups on the graphite support, which serve as anchorage sites for the platinum particles. Site covering is caused by products originating from the graphite support, which are formed as a result of the reductive treatments. When performing the aqueous phase oxidation of methyl $\alpha$-D-glucopyranoside at $323 \mathrm{~K}$ and a $\mathrm{pH}$ of 9, catalyst modifications are small under oxidative conditions. Exposure of the catalyst for several hours to methyl $\alpha=\mathrm{D}$-glucopyranoside under the same conditions but in the absence of oxygen causes site covering.

(c) 1997 A cademic Press

\section{INTRODUCTION}

Partial oxidations of alcohols or carbohydrates are interesting processes for the production of valuable chemicals. The oxidation of primary alcohols to aldehydes or carboxylic acids and of secondary alcohols to ketones can be performed with molecular oxygen in aqueous media over supported platinum and palladium catalysts (1-4). E specially for carbohydrate chemistry the mild reaction conditions and high selectivity are very attractive. However, catalyst deactivation is often reported and forms the major bottleneck for the commercialization of these processes. Four deactivation mechanisms can be distinguished:

\footnotetext{
${ }^{1}$ To whom correspondence should be addressed. E-mail: margriet@chem.tue.nl.
}

(i) Deactivation by over-oxidation or oxygen poisoning has received the most attention. It has been reported for the oxidation of primary alcohols (5-10), secondary alcohols $(8,10-12)$, and carbohydrates $(10,13-19)$. It is generally accepted that over-oxidation is caused by the strong adsorption of oxygen or oxygen-containing species at the platinum surface $(16-18,20,21)$. The catalyst activity is easily recovered by a mild in-situ reduction $(11,13-16,18)$ or is avoided by regulation of the oxygen supply $(3,4)$, application of diffusion-stabilized catalysts $(3,4)$, or the addition of promoter metals to the platinum catalyst $(9,10)$.

(ii) Covering of adsorption sites ("site covering") by major products or minor side products is frequently reported as a cause of deactivation. In the field of carbohydrate oxidation product adsorption was found to deactivate the catalyst for the oxidation of $\mathrm{D}$-glucose (22) and D-gluconic acid (23) in acidic media. In electrochemical oxidations of alcohols in acidic media, $\mathrm{CO}$ from aldehyde intermediates was found to cover active sites $(7,24,25)$, but no $\mathrm{CO}$ poisoning was observed for $\mathrm{D}$-glucose oxidation (22). In alkaline media CO is oxidized under reaction conditions (4) and is present in small amounts (26). In neutral or alkaline media side products may be produced, often via aldol dimerization or polymerization, which may cover irreversibly the active site $(4-6,11,12)$. A Iso, during the initial reductive pretreatment of the catalyst in aqueous media, which is often performed in the presence of the alcohol or carbohydrate to be oxidized, the platinum surface is covered by dehydrogenation products $(4,10,18,19)$. Subsequent oxidation removes poisoning species such as $\mathrm{CO}$ (4), but other side products may still cover active sites (19).

(iii) Metal leaching, the loss of an active metal via the dissolution of metal ions, often constitutes the main reason why a process is not commercially feasible. Especially in the presence of certain anions or complexing agents like carbohydrates and their oxidation products, dissolution of metals is enhanced $(4,16,19)$. D issolution and loss of active metal is not frequently reported, because many oxidations are carried out in batch reactors for relatively short reaction 
times. H owever, upon re-use of the catalyst (8) or after careful characterization of used catalysts or analysis of the liquid phase $(10,18,19)$, a decrease of the catalyst metal content was observed. D uring continuous oxidation of methyl $\alpha$-Dglucopyranoside to sodium methyl $\alpha$-D-glucuronate a platinum content of 2-4 ppm was measured in the solution (16).

(iv) $M$ etal particle growth, just like metal leaching, is observed only after prolonged oxidation. Schuurman et al. (16) explain the irreversible deactivation observed for the oxidation of methyl $\alpha$-D-glucopyranoside as being the result of recrystallization via dissolution and subsequent redeposition of platinum ions. In this so-called O stwald ripening mechanism large particles grow at the expense of smaller ones, resulting in an increase of the average metal particle diameter (27). Other mechanisms have been proposed such as two-dimensional 0 stwald ripening, a mechanism in which platinum atoms migrate on the support surface (28), or an electro-recrystallization mechanism in which local cells are formed between large and small platinum particles, causing platinum ion complex migration compensated by electron transport over the support surface (29).

The aim of this paper is to describe the effects of different environments and reaction conditions on a platinumon-graphite catalyst in terms of site covering and particle growth. Particle growth is studied by transmission electron microscopy (TEM) and X-ray diffraction (XRD). Site covering can be derived from $\mathrm{CO}$ chemisorption, when the results are compared to TEM and XRD. Deactivation is often only clearly observed after prolonged use of the catalyst. Therefore gas phase and aqueous phase treatments of the platinum-on-graphite catalyst are performed under extreme conditions to accelerate site covering and particle growth. The mechanisms for site covering and particle growth observed as a result of these treatments are compared to the deactivation observed for the continuous oxidation of methyl $\alpha$-D-glucopyranoside to sodium 1-o-methyl glucuronate.

\section{EXPERIME NTAL}

Fresh Catalyst

The fresh platinum on a high-surface-area graphite catalyst (Pt/HSA ) was prepared according to the procedure of R ichard and G allezot (30). B atches of $8 \times 10^{-3} \mathrm{~kg} \mathrm{H} \mathrm{SA} \mathrm{G}$ (Johnson M atthey, CH 10213) with a BET surface area of $2.89 \times 10^{5} \mathrm{~m}^{2} \mathrm{~kg}^{-1}$ were activated in air at a flow rate of $5 \times 10^{-6} \mathrm{~N} \mathrm{~m}^{3} \mathrm{~s}^{-1}$ at $773 \mathrm{~K}$ for $5 \mathrm{~h}$, resulting in a carbon burn-off of $21 \mathrm{wt} \%$. The air-oxidized graphite was stirred in a 13 wt\% sodium hypochlorite solution (Janssen p.a.) at a concentration of $80 \mathrm{~kg} \mathrm{~m}^{-3}$ for $24 \mathrm{~h}$ at room temperature. The graphite was carefully washed with ultra pure M illipore water (18 $\mathrm{M} \Omega \mathrm{cm}$ ), which was used for all preparations, aqueous phase treatments, and reactions. The graphite was filtered on a $0.45-\mu \mathrm{m} \mathrm{M}$ illipore filter and dried at $323 \mathrm{~K}$ and $5 \mathrm{kPa}$. Competitive ion-exchange was used by drop-wise adding a $16 \mathrm{wt} \%$ tetrammine platinum hydroxide solution, $\mathrm{Pt}\left(\mathrm{NH}_{3}\right)_{4}(\mathrm{OH})_{2}$ (D egussa), to $50 \mathrm{~kg} \mathrm{~m}^{-3}$ graphite in $1 \mathrm{M}$ ammonia (Merck p.a.) until a platinum concentration of $10 \mathrm{~kg} \mathrm{~m}^{-3}$ was reached. The alkaline solution was stirred for $24 \mathrm{~h}$ at room temperature. The catalyst was carefully washed, filtered on a $0.45-\mu \mathrm{m}$ filter, dried at $323 \mathrm{~K}$ and $5 \mathrm{kPa}$, and reduced in batches of $8 \times 10^{-3} \mathrm{~kg}$ in hydrogen at a flow rate of $5 \times 10^{-6} \mathrm{~N} \mathrm{~m}^{3} \mathrm{~s}^{-1}$ at $573 \mathrm{~K}$ for $3 \mathrm{~h}$. The platinum content amounted to $3.4 \mathrm{wt} \%$ and the BE T surface area was $1.02 \times 10^{5} \mathrm{~m}^{2} \mathrm{~kg}_{\text {cat }}^{-1}$.

\section{$\mathrm{G}$ as $\mathrm{P}$ hase Treatments}

The fresh catalyst was treated by heating $2.5 \times 10^{-4} \mathrm{~kg}$ in hydrogen, nitrogen, or air at a flow rate of $5 \times 10^{-6} \mathrm{~N} \mathrm{~m}^{3} \mathrm{~s}^{-1}$ at $773 \mathrm{~K}$ for $2 \mathrm{~h}$. Treatment in air was followed by reduction in hydrogen at $573 \mathrm{~K}$ for $1 \mathrm{~h}$. A fter treatment in hydrogen and nitrogen the increase of the platinum content was negligible, whereas, after treatment in air the platinum content had increased by a factor of four, due to platinum-catalyzed carbon burn-off (31).

\section{A queous P hase Treatments}

A $4 \times 10^{-4} \mathrm{~m}^{3}$ stirred glass tank reactor equipped with a glass stirrer was filled with 2.5 to $10 \mathrm{~kg} \mathrm{~m}^{-3}$ fresh catalyst in $0.2 \times 10^{-3} \mathrm{~m}^{3} \mathrm{M}$ illipore water $(\mathrm{pH} \approx 7), 100 \mathrm{~mol} \mathrm{~m}^{-3} \mathrm{H} \mathrm{ClO}_{4}$ $(\mathrm{pH}=1)$, or $100 \mathrm{~mol} \mathrm{~m}^{-3} \mathrm{NaOH}(\mathrm{pH}=13)$. The slurry was stirred in a nitrogen or hydrogen atmosphere at $363 \mathrm{~K}$ or in an oxygen atmosphere at $323 \mathrm{~K}$ at a gas flow rate of $3 \times 10^{-6} \mathrm{~N} \mathrm{~m}^{3} \mathrm{~s}^{-1}$.

\section{Oxidation of M ethyl $\alpha$-D-G lucopyranoside:}

E quipment and $\mathrm{P}$ rocedure

A continuous flow three-phase slurry reactor of $0.7 \times$ $10^{-3} \mathrm{~m}^{3}$ volume was used. The glass reactor was equipped with a glass stirrer with internal gas circulation, a $\mathrm{pH}$ electrode ( $R$ adiometer PH C 2402), an oxygen electrode (Ingold 341003005), and a membrane filter of $0.45 \mu \mathrm{m}$ (M illipore G V W P09050) to retain the catalyst. The temperature was measured with a Pt-100 probe and controlled by a water bath (B eun de R onde CS6 and R 22). The reactor was operated at atmospheric pressure at a constant gas flow rate of $3 \times 10^{-6} \mathrm{~N} \mathrm{~m}^{3} \mathrm{~s}^{-1}$.

B efore the start of the oxidation reaction $0.7 \times 10^{-3} \mathrm{~kg}$ fresh catalyst was prereduced in $0.35 \times 10^{-3} \mathrm{~m}^{3}$ water at $363 \mathrm{~K}$ for $1.8 \times 10^{3} \mathrm{~s}$ in a hydrogen flow. U nder a nitrogen atmosphere the reactor was cooled to $323 \mathrm{~K}$ and the water was removed. A solution of methyl $\alpha$-D-glucopyranoside (Fluka) and sodium methyl $\alpha$-D-glucuronate was added, which was previously prepared by a separate batch oxidation reaction of methyl $\alpha$-D-glucopyranoside under identical reaction conditions and stopped at the same conversion level as the reaction to be performed. The reaction was 
started by replacing the nitrogen flow with an oxygen flow. The methyl $\alpha$-D-glucopyranoside and sodium hydroxide solutions were added to the reactor simultaneously at equal flow rates with a tubing pump (M asterflex 7523-35) equipped with two equal pump heads. The inlet liquid flow rate was adapted to the rate of production of sodium 1-o-methyl glucuronate by a feedback PID -control (E urotherm 940D) based on the pH measurement of the reaction mixture. In this way the concentration of methyl $\alpha$-D-glucopyranoside and sodium methyl $\alpha$-D-glucuronate were kept constant despite catalyst deactivation, provided that catalyst deactivation did not result in selectivity changes. A nalysis of the reaction mixture, performed off-line with a HPLC analysis described elsewhere (16), confirmed that the concentrations of methyl $\alpha$-D-glucopyranoside and sodium methyl $\alpha$-D-glucuronate were constant throughout the reaction. The carbon balance was kept within $1 \%$ at the applied conversion level. The inlet liquid flow rate was measured by recording the weight loss of the liquid supply vessels with two Sartorius I8100P balances. The outlet liquid flow rate was controlled via PID -control (E urotherm 940D) of a tubing pump (M asterflex). This controller takes as input the differential pressure (Fischer \& Porter 50D PF 100-3) between the head space and the bottom (tip of the immersion pipe) of the reactor. In this way the total liquid volume of the reactor was kept constant within $5 \times 10^{-6} \mathrm{~m}^{3}$. The stirrer speed during reaction was $25 \mathrm{~s}^{-1}$, ensuring good contact of the three phases. It was verified that the kinetic measurements were free of mass and heat transfer limitations.

R egeneration of the catalyst to overcome over-oxidation was performed in situ. The oxygen flow was successively replaced by nitrogen, hydrogen, and nitrogen for $1.8 \times 10^{3} \mathrm{~S}$. The $\mathrm{pH}$, temperature, and concentrations were maintained constant during regeneration.

\section{Catalyst Characterization}

Catalyst samples from liquid phase experiments were filtered on a $0.45 \mu \mathrm{m}$ membrane filter (Schleicher and Schull R C55 or M illipore GVWP09050), carefully washed with Millipore water and dried at $323 \mathrm{~K}$ and $5 \mathrm{kPa}$.

The platinum content of the catalysts was determined in duplicate by dissolving the platinum in concentrated $\mathrm{HCl} / \mathrm{H} \mathrm{NO}_{3}$ (3:1, M erck p.a.) followed by the removal of the nitric acid by adding hydrochloric acid and evaporating three times. A yellow platinum tin chloride complex was formed by adding a hydrochloric acid containing tin chloride solution ( $M$ erck p.a.) and the extinction was measured at $403 \mathrm{~nm}(32,33)$. The standard deviation was found to be smaller than 0.1 wt\% for all measurements. The platinum concentration in the liquid phase was determined from the extinction of the platinum tin chloride complex, which was measured at $403 \mathrm{~nm}$ with a diode-array detector with a detection limit of $1 \times 10^{-4} \mathrm{~mol} \mathrm{~m}^{-3}$.
The specific surface area was measured as the BET surface area with a M icromeritics A SA P 2000 instrument. A n exact amount of catalyst or graphite support was dried at $383 \mathrm{~K}$ for $1 \mathrm{~h}$ under vacuum in the sample tube prior to measurement.

The fraction of platinum atoms exposed was determined by $\mathrm{CO}$ pulse chemisorption using a modified gas chromatograph (Carlo E rba 4300) equipped with a thermal conductivity detector (TCD). H ydrogen and helium were purified by an oxygen and moisture filter and the carbon monoxide $(99.997 \%)$ was used without further purification. Prior to measurement all catalyst samples were dried at $323 \mathrm{~K}$ at $5 \mathrm{kPa}$ overnight. A $\mathrm{n}$ exact amount of catalyst was reduced in a Pyrex glass plug flow reactor at $373 \mathrm{~K}$ for $2 \times 10^{3} \mathrm{~s}$ in $3 \times 10^{-7} \mathrm{~N} \mathrm{~m}^{3} \mathrm{~s}^{-1}$ hydrogen. $\mathrm{CO}$ was adsorbed in a helium flow of $3 \times 10^{-7} \mathrm{~N} \mathrm{~m}^{3} \mathrm{~s}^{-1}$ at $273 \mathrm{~K}$. The fraction exposed, $\mathrm{FE}^{\mathrm{CO}}$, was calculated assuming an adsorption stoichiometry of $\mathrm{CO}_{\mathrm{ads}}: \mathrm{Pt}_{\mathrm{s}}=1$. E very catalyst sample was measured in duplicate according to the procedure described above. The standard deviation for the obtained FE ${ }^{\mathrm{CO}}$ was smaller than 0.01 for all measurements.

Transmission electron microscopy (TEM) micrographs were obtained with a JE O L 1200 E X microscope. The samples were ultrasonically dispersed in tetrachloromethane p.a. or ethanol p.a. and the suspension was brought onto 400 mesh copper grids coated with a carbon support film (TA A B ). A n accelerating potential of $120 \mathrm{kV}$ was used with a microscope magnification between 50,000 and 500,000. The resulting micrographs were analyzed with a scale magnifying glass (Peak) with a magnification of 10 and an accuracy of $0.1 \mathrm{~mm}$ to obtain the platinum particle diameter distribution. D epending on the quality of the micrographs and the magnification applied, between 169 and 569 platinum particles were counted per catalyst sample.

The number, surface area, and weight averaged platinum particle diameter were determined from the distribution according to L emaître et al. (34).

$$
\begin{aligned}
& d_{\mathrm{n}}^{\text {TEM }}=\frac{\sum_{i} n_{i} d_{i}}{\sum_{i} n_{i}} ; \quad d_{\mathrm{s}}^{\mathrm{TEM}}=\frac{\sum_{i} n_{i} d_{i}^{3}}{\sum_{i} n_{i} d_{i}^{2}} ; \\
& d_{\mathrm{w}}^{\text {TEM }}=\frac{\sum_{i} n_{i} d_{i}^{4}}{\sum_{i} n_{i} d_{i}^{3}}
\end{aligned}
$$

The sample standard deviation for the number, surface area, and weight averaged platinum particle diameter is obtained from:

$$
\begin{aligned}
\sigma_{\mathrm{n}} & =\sqrt{\frac{\sum_{i} n_{i}\left(d_{i}-d_{\mathrm{n}}\right)^{2}}{\sum_{i} n_{i}} ;} \quad \sigma_{\mathrm{s}}=\sqrt{\frac{\sum_{i} n_{i} d_{i}^{2}\left(d_{i}-d_{\mathrm{s}}\right)^{2}}{\sum_{i} n_{i} d_{i}^{2}}} ; \\
\sigma_{\mathrm{w}} & =\sqrt{\frac{\sum_{i} n_{i} d_{i}^{3}\left(d_{i}-d_{\mathrm{w}}\right)^{2}}{\sum_{i} n_{i} d_{i}^{3}}}
\end{aligned}
$$


and the $95 \%$ confidence interval for $d_{j}^{\top E M}(j=n, s$, or $w)$ is

$$
d_{j}^{\mathrm{TEM}} \pm \frac{1.96 \sigma_{j}}{\sqrt{n}}
$$

$X$-ray diffraction (XRD) was performed unless the amount of catalyst was insufficient to fill the sample holder. XRD was determined using $\mathrm{CuK}_{\alpha}$ radiation $(\lambda=$ $0.15418 \mathrm{~nm}$ ) and a CG R focusing monochromator (curved quartz single crystal). The curve position sensitive detector (INEL CPS120) had an angular range of $5-120^{\circ}$ $(2 \theta)$ and a resolution of approximately $0.03^{\circ}(2 \theta)$. Spectra were recorded for $2.4 \times 10^{3} \mathrm{~s}$ in the reflection or transmission mode. For the line analysis and deconvolution SIEMENS/SOCA BIM (FIT) software was used, as graphite lines partially overlapped the Pt(111) line. The average platinum particle diameter was calculated from the Warren-modified Scherrer equation (35):

$$
d_{\mathrm{w}}^{\mathrm{XRD}}=\frac{0.9 \lambda}{\Delta(2 \theta) \cos \theta} \quad \text { with } \Delta(2 \theta)=\sqrt{\beta_{1 / 2}^{2}-b^{2}}
$$

with $\lambda=0.15418 \mathrm{~nm}, \theta$ is the Bragg angle, $\beta_{1 / 2}$ is the linewidth at half maximum in radians, and $b=0.00182$ radians $\left(0.104^{\circ}\right)$, the instrumental line broadening being determined experimentally with bulk platinum with high grain size.

Particles as small as $1.5 \mathrm{~nm}$ could be detected by line broadening analysis. In the review by Gallezot (35) other examples are mentioned, where particle diameters are established by line broadening analysis which are smaller than the generally accepted detection limit of about $4 \mathrm{~nm}$. Sashital etal. (36) reported examinations with X -ray diffraction of platinum particles on silica as small as $2.5 \mathrm{~nm}$ and B ergeret et al. (37) established particle diameters as small as $1.5 \mathrm{~nm}$ by line broadening analysis. The accuracy of the measurement of such small particles is, of course, rather limited.

In order to compare the results obtained with XRD, $T E M$, and $C O$ chemisorption, the exposed fraction determined by $\mathrm{CO}$ chemisorption, $\mathrm{FE}^{\mathrm{CO}}$, was converted to the surface-area-averaged particle diameter, $d_{\mathrm{s}}^{\mathrm{CO}}$, assuming hemispherical particles and $1.42 \times 10^{19}$ platinum atoms per square meter (38):

$$
d_{\mathrm{s}}^{\mathrm{CO}}=\frac{1.3 \times 10^{-9}}{\mathrm{FE}^{\mathrm{CO}}} .
$$

O bviously the application of Eq. [5] is only allowed when the platinum surface atoms are available for $\mathrm{CO}$ chemisorption, i.e., are not covered by adspecies on which $\mathrm{CO}$ does not chemisorb.

\section{RESULTS}

Fresh Catalyst

A TEM micrograph and the platinum particle diameter distribution of the fresh catalyst are presented in Figs. 1 and $2 \mathrm{a}$, respectively. It is a well defined monodisperse catalyst in agreement with the results of $\mathrm{R}$ ichard and $\mathrm{G}$ allezot (30). The platinum particle diameter ranges from the detection limit to $2.5 \mathrm{~nm}$. The results of the characterization of the fresh catalyst with TEM, CO chemisorption, and XRD are given in Table 1 . With XRD a weight-averaged diameter, $d_{w}$, and with chemisorption techniques a surfacearea-averaged diameter, $d_{s}$, are obtained from the exposed fraction of metal atoms (38). From the platinum particle diameter distribution obtained with TEM the numberaveraged, surface-area-averaged, and weight-averaged diameters were calculated.

For the fresh catalyst the observed order is $d_{n}^{\text {TEM }}<$ $d_{\mathrm{w}}^{\mathrm{XRD}}<d_{\mathrm{s}}^{\mathrm{TEM}}<d_{\mathrm{w}}^{\mathrm{TEM}}<d_{\mathrm{s}}^{\mathrm{CO}}$. This is in good agreement with the generally observed order $d_{\mathrm{n}}^{\mathrm{TEM}}<d_{\mathrm{w}}^{\mathrm{XRD}}<d_{\mathrm{s}}^{\text {chem }}$. For example, Scardi and A ntonucci (39) reported this order for platinum on carbon catalysts using cyclic voltammetry as the chemisorption technique, obtaining the platinum surface area from the Coulombic charge transferred during hydrogen adsorption.

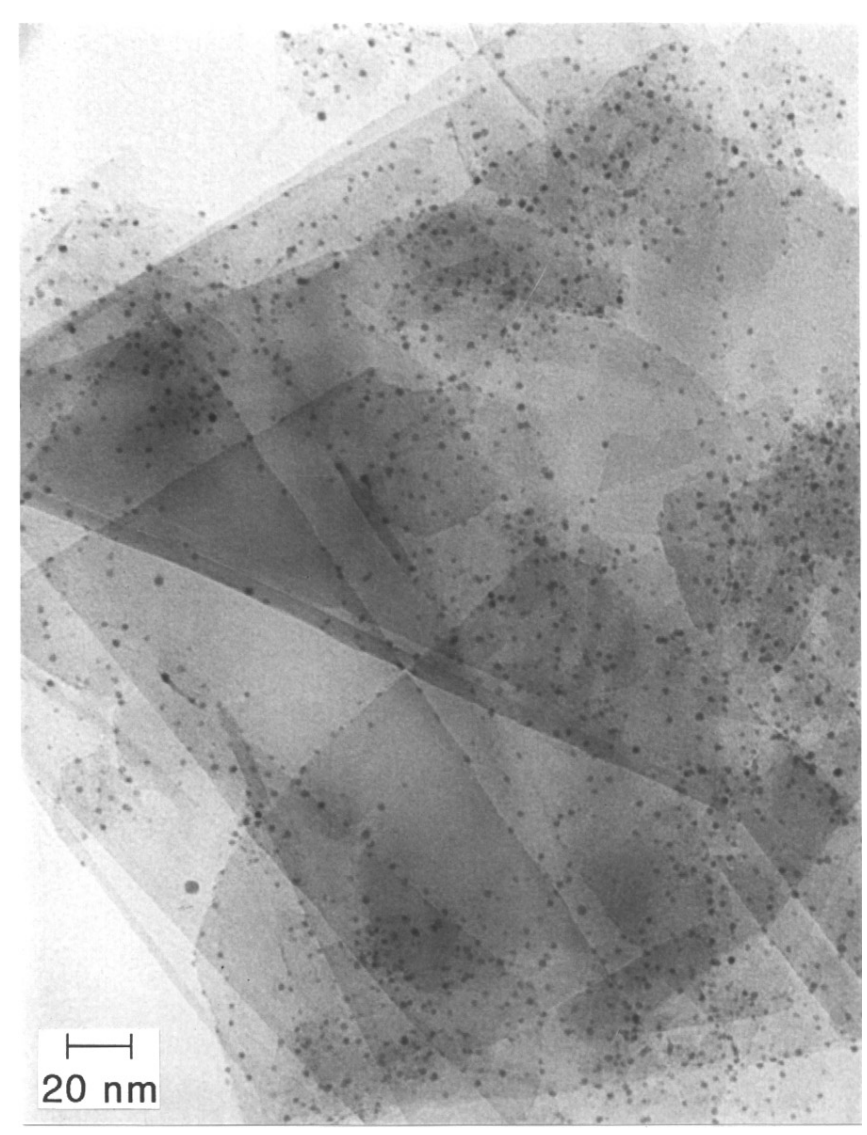

FIG. 1. M icrograph (TEM) of the fresh platinum on graphite catalyst. 
The smaller diameter obtained with X R D compared to $d_{\mathrm{w}}^{\mathrm{TEM}}$ may be attributed to the inaccuracy of line broadening analysis for small particles. The width of the XRD lines is affected by internal disorder and strain of the platinum particles (40), which is certainly found at the edges of the particles. For small particles this will mean a large decrease of the size of the reflecting crystalline structure. Furthermore, particles envisaged with TE M as one particle may actually consist of smaller crystalline structures. A s a consequence $d_{\mathrm{w}}^{\mathrm{XRD}}$ will be smaller than $d_{\mathrm{w}}^{\mathrm{TEM}}$.

The diameter obtained with CO chemisorption, $d_{\mathrm{s}}^{\mathrm{CO}}$, is larger than $d_{\mathrm{s}}^{\text {TEM }}$ for several possible reasons. First, the assumption of hemispherical particles and the amount of platinum atoms per surface area $\left(1.42 \times 10^{19} \mathrm{~m}^{-2}(38)\right)$ may be incorrect. $O$ ften a different constant is used in $\mathrm{E}$ q. (5): $d=1.08 \times 10^{-9} / F E(41)$. Further, the assumed adsorption
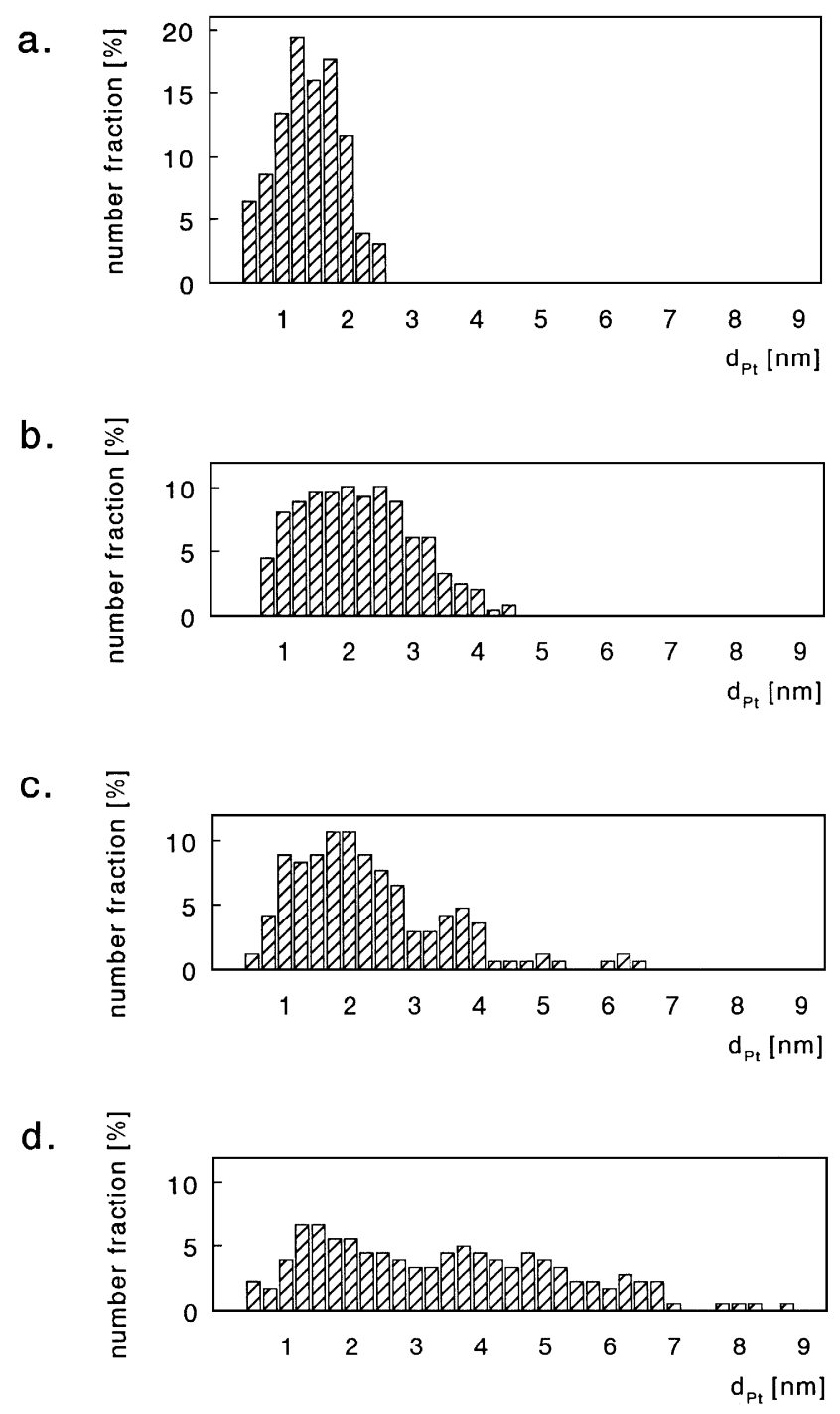

FIG. 2. Platinum particle diameter distribution of the fresh catalyst (a) and after reductive treatment in a hydrogen atmosphere in $0.1 \mathrm{M} \mathrm{N} \mathrm{aO} \mathrm{H}$ $(\mathrm{pH}=13)$ at $363 \mathrm{~K}$ for (b) $0.3 \times 10^{3}$, (c) $3.6 \times 10^{3}$, and (d) $2.5 \times 10^{5} \mathrm{~s}$.

\section{TABLE 1}

The N umber, Surface Area, and Weight-Averaged Platinum Particle Diameter Obtained by TEM $\left(d_{\mathrm{n}}^{\mathrm{TEM}}, d_{\mathrm{s}}^{\mathrm{TEM}}\right.$, and $\left.d_{\mathrm{w}}^{\mathrm{TEM}}\right)$, the Fraction Exposed, and Platinum Particle Diameter Measured by $\mathrm{CO}$ Chemisorption (FE ${ }^{\mathrm{CO}}$ and $d_{\mathrm{s}}^{\mathrm{CO}}$ ), and the Platinum Particle Diameter Measured by X-R ay Diffraction ( $d_{\mathrm{w}}^{\mathrm{XRD}}$ )

\begin{tabular}{|c|c|c|c|c|c|c|}
\hline Catalyst $^{a}$ & $\begin{array}{l}d_{\mathrm{n}}^{\mathrm{TEM}} \\
{[\mathrm{nm}]}\end{array}$ & $\begin{array}{l}d_{\mathrm{s}}^{\mathrm{TEM}} \\
{[\mathrm{nm}]}\end{array}$ & $\begin{array}{l}d_{\mathrm{w}}^{\mathrm{TEM}} \\
{[\mathrm{nm}]}\end{array}$ & $\begin{array}{c}\mathrm{FE}^{\mathrm{CO}} \\
{\left[\frac{\mathrm{mol}_{\mathrm{pts}}}{\mathrm{mol} \mathrm{lpt}_{\mathrm{pt}}}\right]}\end{array}$ & $\begin{array}{l}d_{\mathrm{s}}^{\mathrm{CO}} \\
{[\mathrm{nm}]}\end{array}$ & $\begin{array}{l}d_{\mathrm{w}}^{\mathrm{X} R \mathrm{D}} \\
{[\mathrm{nm}]}\end{array}$ \\
\hline Fresh & $1.45 \pm 0.04$ & $1.70 \pm 0.04$ & $1.81 \pm 0.04$ & 0.56 & 2.3 & $1.5^{b}$ \\
\hline $\mathrm{H}_{2} \mathrm{G}$ & $2.0 \pm 0.1$ & $2.9 \pm 0.1$ & $3.3 \pm 0.1$ & 0.60 & 2.2 & - \\
\hline $\mathrm{N}_{2} \mathrm{G}$ & $1.7 \pm 0.1$ & $2.4 \pm 0.1$ & $2.9 \pm 0.1$ & 0.57 & 2.3 & - \\
\hline $\mathrm{O}_{2} \mathrm{G}$ & $6.5 \pm 0.4$ & $14.0 \pm 0.5$ & $16.9 \pm 0.5$ & 0.09 & 14 & 25 \\
\hline $\mathrm{H}_{2} \mathrm{~B} 1-0.3$ & $2.2 \pm 0.1$ & $2.8 \pm 0.1$ & $3.0 \pm 0.1$ & 0.37 & 3.5 & - \\
\hline $\mathrm{H}_{2} \mathrm{~B} 1-3.6$ & $2.3 \pm 0.2$ & $3.5 \pm 0.2$ & $4.2 \pm 0.2$ & 0.26 & 5.0 & - \\
\hline $\mathrm{H}_{2} \mathrm{~B} 1-250$ & $3.4 \pm 0.3$ & $5.2 \pm 0.3$ & $5.7 \pm 0.2$ & 0.09 & 14 & 3.4 \\
\hline $\mathrm{H}_{2} \mathrm{~B} 2-250$ & $2.4 \pm 0.2$ & $3.9 \pm 0.2$ & $4.9 \pm 0.3$ & 0.18 & 7.2 & 3.1 \\
\hline $\mathrm{H}_{2} \mathrm{~B} 2-250 \mathrm{R}$ & $2.2 \pm 0.2$ & $3.7 \pm 0.2$ & $4.6 \pm 0.2$ & 0.25 & 5.2 & - \\
\hline $\mathrm{H}_{2} \mathrm{~L}$ & $1.60 \pm 0.05$ & $1.90 \pm 0.05$ & $2.03 \pm 0.04$ & 0.41 & 3.2 & $1.6^{b}$ \\
\hline M 1 & $1.39 \pm 0.06$ & $1.79 \pm 0.06$ & $1.95 \pm 0.06$ & 0.38 & 4.8 & $1.5^{b}$ \\
\hline M 4 & $1.53 \pm 0.05$ & $1.88 \pm 0.04$ & $2.00 \pm 0.04$ & 0.42 & 3.1 & $1.7^{b}$ \\
\hline M 7 & $1.64 \pm 0.04$ & $1.90 \pm 0.04$ & $2.02 \pm 0.04$ & 0.27 & 4.8 & - \\
\hline
\end{tabular}

\footnotetext{
a The catalyst codes are explained in the text.

${ }^{b} \mathrm{D}$ ue to the determination by line broadening analysis the accuracy is limited.
}

stoichiometry of $\mathrm{CO}_{\text {ads }} / \mathrm{Pt}_{\mathrm{s}}=1$ is too large for small particles $(41,42)$.

\section{G as P hase Treatments}

The growth of platinum particles upon heat treatment in the presence of a gas phase was investigated by heating the fresh catalyst at $773 \mathrm{~K}$. Table 1 shows the results of this treatment in a hydrogen, nitrogen, and oxygen atmosphere, the catalyst samples being indicated by $\mathrm{H}_{2} \mathrm{G}, \mathrm{N}_{2} \mathrm{G}$, and $\mathrm{O}_{2} \mathrm{G}$. $\mathrm{H}$ eating in a hydrogen or nitrogen atmosphere results in $\mathrm{a}$ small increase of the average platinum particle diameter and a small decrease of the fraction exposed, $\mathrm{FE}^{\mathrm{CO}}$. O xidation of the fresh catalyst in air results in a large increase of the average platinum particle diameter. This is caused by the platinum-catalyzed oxidation of the graphite support (31), resulting in a 75 wt\% carbon burnoff. B ecause of this very high burnoff the support is destroyed, together with the anchorage sites of the platinum particles, and platinum particles will migrate over the support surface, collide, and coalesce. The effect of oxidation at $773 \mathrm{~K}$ on the diameter of the platinum particles is shown in Fig. 3 , in which platinum particles with a diameter of up to $30 \mathrm{~nm}$ can be observed.

\section{A queous P hase Treatments}

Figure 4 shows the exposed fraction of platinum atoms after aqueous phase treatment of the fresh catalyst at $\mathrm{pH}=1$, 7 , and 13 in a hydrogen and nitrogen atmosphere at $363 \mathrm{~K}$ and in an oxygen atmosphere at $323 \mathrm{~K}$ for $20 \mathrm{~h}$. The FE ${ }^{\mathrm{CO}}$ 


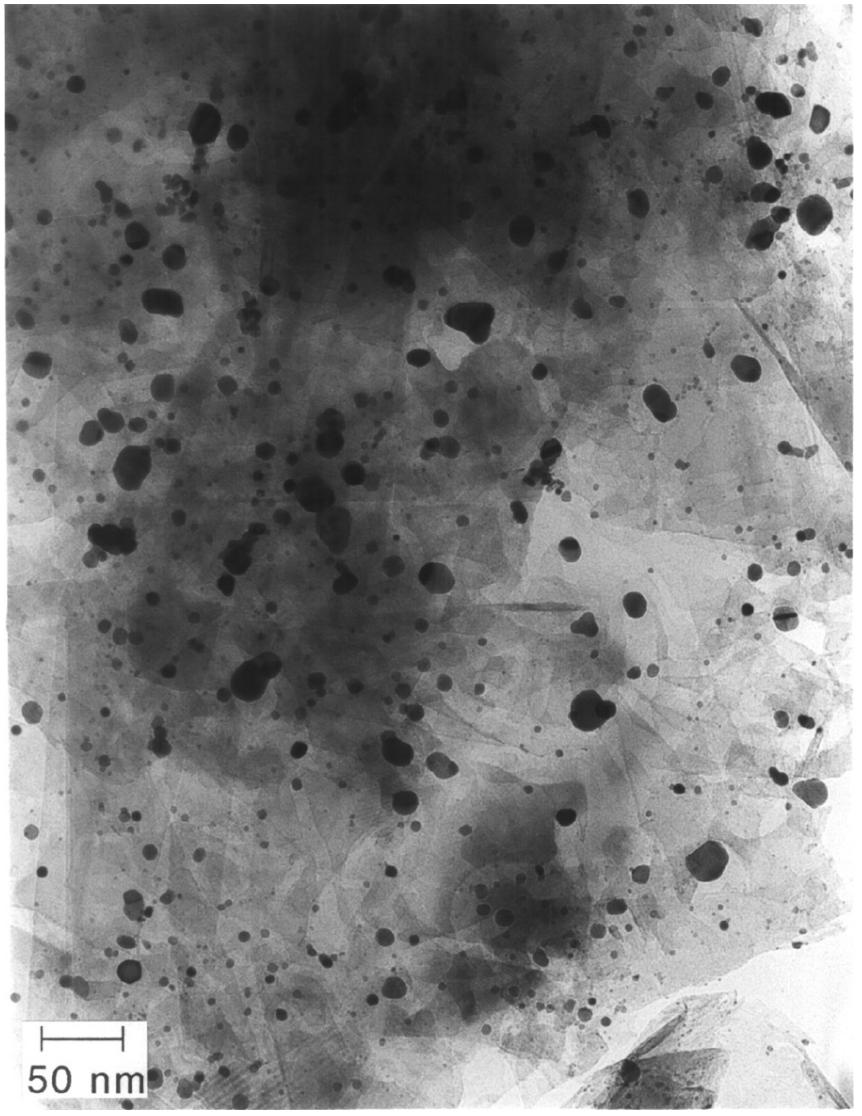

FIG. 3. M icrograph (TEM) of catalyst sample $\mathrm{O}_{2} \mathrm{G}$ after oxidation in air at $773 \mathrm{~K}$ for $2 \mathrm{~h}$.

decreases with increasing $\mathrm{pH}$, the strongest effect being observed for hydrogen.

In order to study the effect of the hydrogen treatment at $\mathrm{pH}=13$ the fresh catalyst was treated for $250 \times 10^{3} \mathrm{~s}$ at a catalyst concentration of $5 \mathrm{~kg} \mathrm{~m}^{-3}$. Figure 5 shows a sharp decrease of the exposed fraction of platinum atoms, $\mathrm{FE}^{\mathrm{CO}}$, as a function of time for this experiment. Three samples taken at $0.3,3.6$, and $250 \times 10^{3} \mathrm{~s}$, indicated by $\mathrm{H}_{2} \mathrm{~B} 1-0.3$, $\mathrm{H}_{2} \mathrm{~B}$ 1-3.6, and $\mathrm{H}_{2} \mathrm{~B}$ 1-250, were al so characterized with TE M and $X R D$. The results are listed in Table 1 . The decrease of the $F E^{C O}$ from 0.56 for the fresh catalyst to 0.09 after $250 \times 10^{3} \mathrm{~s}$ is accompanied by an increase of the average platinum particle diameter. With TE $M$ a gradual increase from $d_{\mathrm{s}}^{\text {TEM }}=1.70$ to $5.2 \mathrm{~nm}$ is observed. The platinum particle diameter distributions of this experiment are depicted in Fig. 2 and it clearly demonstrates platinum particle growth. With XRD an increase from 1.5 to $3.4 \mathrm{~nm}$ was determined.

A nother effect of the treatment at $\mathrm{pH}=13$ in a hydrogen atmosphere is the appearance of platinum aggregates. Figure 6 shows a TEM micrograph of the largest aggregate observed for $\mathrm{H}_{2} \mathrm{~B} 1-250$. The amount and size of these aggregates increases with increasing reduction time. It is not clear whether the aggregates consist of platinum exclusively or whether carbonaceous material is incorporated in

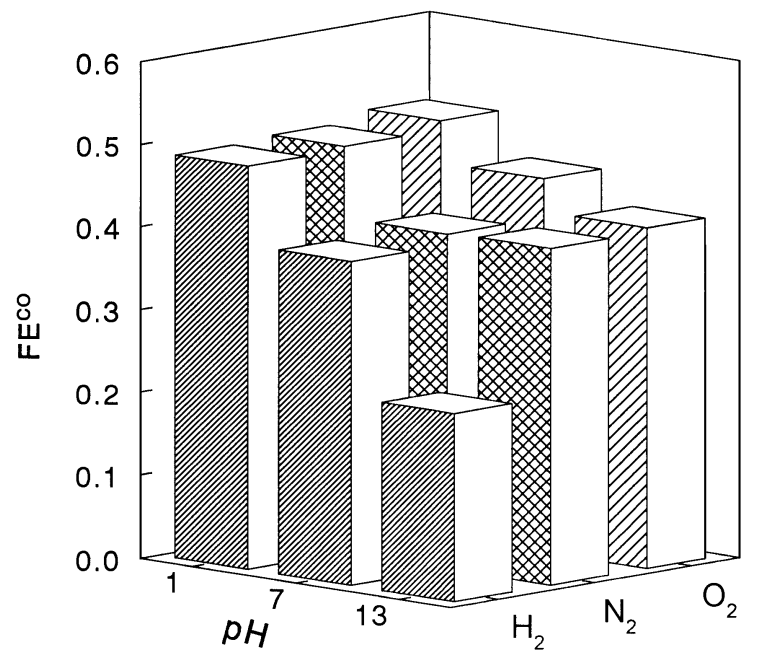

FIG . 4. Fraction exposed measured with $\mathrm{CO}$ chemisorption, $\mathrm{FE}^{\mathrm{CO}}$, as a function of the $\mathrm{pH}$ and atmosphere after a 20-h treatment at $363 \mathrm{~K}$ $\left(\mathrm{H}_{2}\right.$ and $\left.\mathrm{N}_{2}\right)$ or $323 \mathrm{~K}\left(\mathrm{O}_{2}\right)$.

the aggregates. EDX is not a helpful tool in this case because both the catalyst support and the film on the copper grid are composed of carbon, which contributes to the total carbon signal in the EDX spectrum.

$\mathrm{R}$ epeating the reduction experiment at a higher catalyst concentration of $10 \mathrm{~kg} \mathrm{~m}^{-3}$, indicated by $\mathrm{H}_{2} \mathrm{~B} 2-250$ in Table 1 , after $250 \times 10^{3} \mathrm{~s}$ the fraction exposed was 0.18 . A series of treatments with $\mathrm{H}_{2}$ at $\mathrm{pH}=13$ indicated that a higher $\mathrm{NaOH}$ /catalyst ratio resulted in a larger decrease of the fraction exposed. $\mathrm{A} \mathrm{NaOH}$ consumption of $1 \mathrm{~mol} \mathrm{~kg}-1$ or $6 \mathrm{~mol} \mathrm{~mol}_{\mathrm{pt}}^{-1}$ was found for a catalyst concentration of $10 \mathrm{~kg} \mathrm{~m}^{-3}$. The higher $\mathrm{NaOH} /$ catalyst ratio for $\mathrm{H}_{2} \mathrm{~B} \mathrm{1-250}$ compared to $\mathrm{H}_{2} \mathrm{~B} 2-250$ has led to a larger increase of the platinum particle diameter as measured with TEM and XRD and a smaller FE ${ }^{\mathrm{CO}}$, as is clear from Table 1. A Iso,

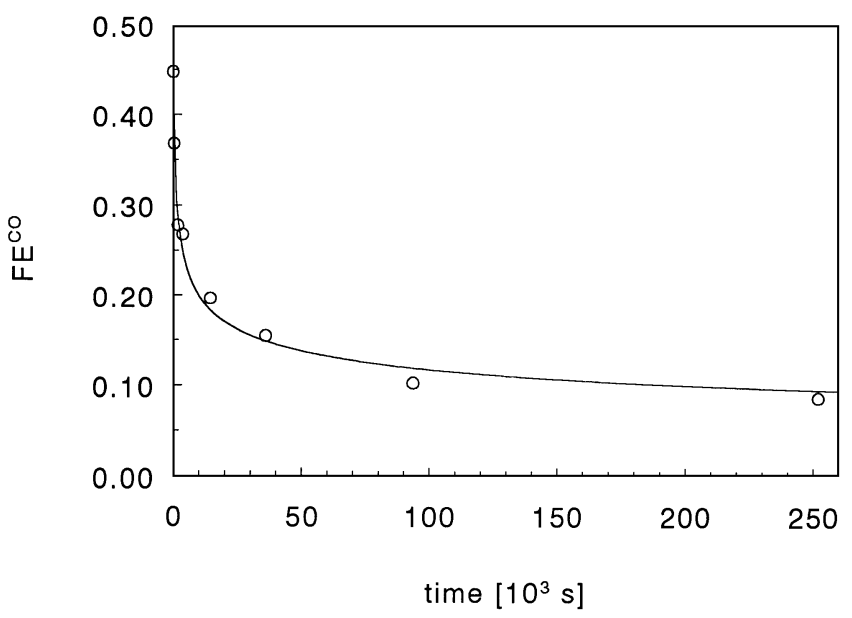

FIG. 5. Fraction exposed measured with $\mathrm{CO}$ chemisorption, $\mathrm{FE}^{\mathrm{CO}}$, upon reductive treatment in a hydrogen atmosphere in $0.1 \mathrm{M} \mathrm{NaOH}$ $(\mathrm{pH}=13)$ at $363 \mathrm{~K}$ as a function of time. 


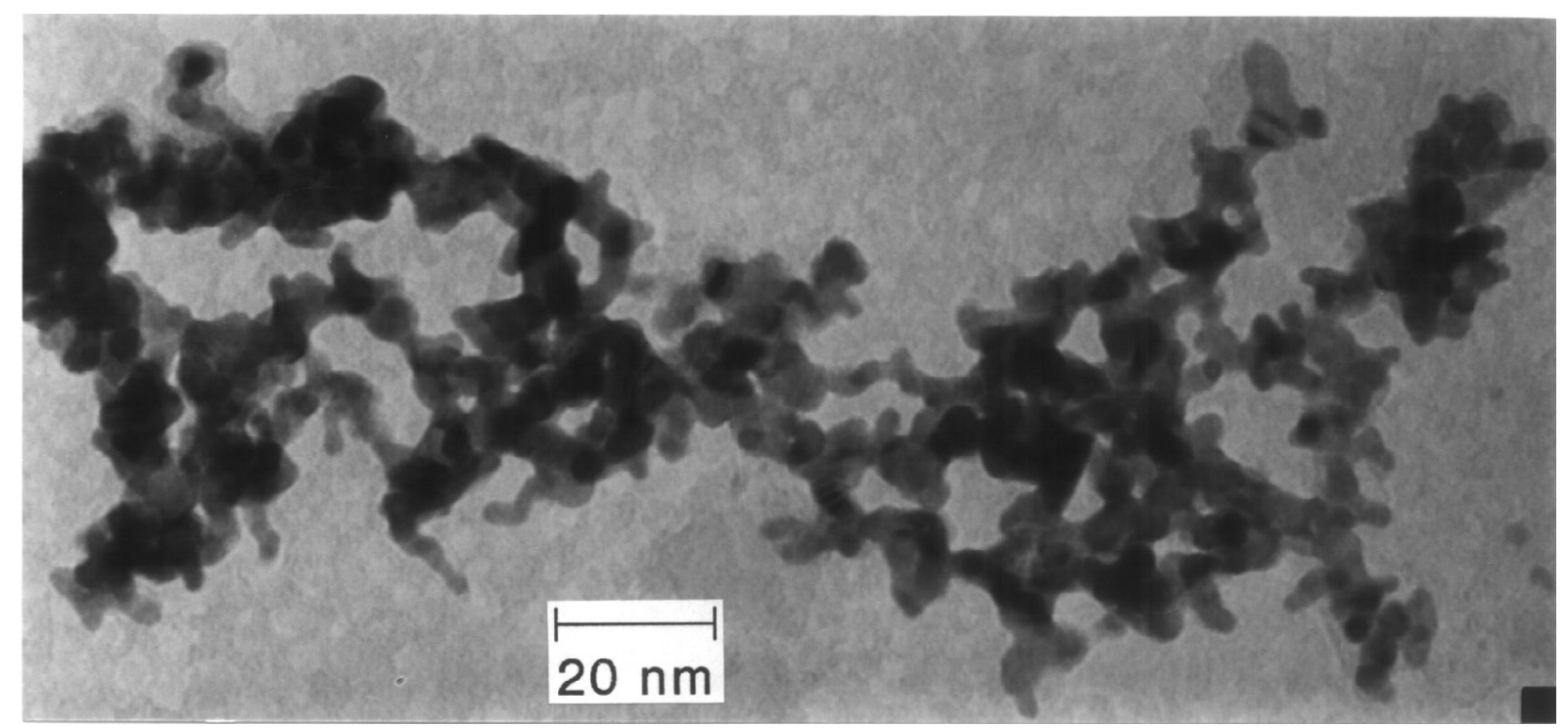

FIG. 6. M icrograph (TE M) of the largest platinum aggregate observed after reductive treatment of the fresh catalyst in a hydrogen atmosphere in $0.1 \mathrm{M} \mathrm{NaOH}(\mathrm{pH}=13)$ at $363 \mathrm{~K}$ for $2.5 \times 10^{5} \mathrm{~s}$.

larger platinum aggregates were observed on the former sample with TEM .

$\mathrm{Next}, \mathrm{H}_{2} \mathrm{~B} 2-250$ was treated in $100 \mathrm{~mol} \mathrm{~m}^{-3} \mathrm{HClO}_{4}$ at $323 \mathrm{~K}$ by applying 4 oxidation reduction cycles indicated in Table 1 as $\mathrm{H}_{2} \mathrm{~B} 2-250 \mathrm{R}$. The $\mathrm{FE}^{\mathrm{CO}}$ recovered to 0.25 . A nother indication that site coverage and particle growth occur simultaneously during treatment with $\mathrm{H}_{2}$ at $\mathrm{pH}=13$ is the fact that the increase of the $d_{\mathrm{s}}^{\mathrm{CO}}$ from $2.3 \mathrm{~nm}$ for the fresh catalyst to $14 \mathrm{~nm}$ for $\mathrm{H}_{2} \mathrm{~B}$ 1-250 is much larger than the increase of the $d_{\mathrm{s}}^{\text {TEM }}$ from 1.70 to $5.2 \mathrm{~nm}$ and the $d_{\mathrm{w}}^{\mathrm{XRD}}$ from 1.5 to $3.4 \mathrm{~nm}$. N ote that it was difficult to measure the average platinum particle diameter with TEM , because of the irregular shape of the platinum particles and the presence of clusters of particlesforming aggregates. This may explain why $d_{\mathrm{w}}^{\text {TE M }}$ is larger than $d_{\mathrm{w}}^{\mathrm{XRD}}$ for $\mathrm{H}_{2} \mathrm{~B} 1-250$ and $\mathrm{H}_{2} \mathrm{~B} 2-250$.

It was verified whether the catalyst was poisoned by impurities originating from the reactor, because after several treatments under hydrogen at $\mathrm{pH}=13$ at $363 \mathrm{~K}$ corrosion of the glass was observed. Combination of energy dispersive $\mathrm{x}$-ray analysis, EDX, with TEM or scanning transmission electron microscopy, STEM , could not reveal the presence of impurities, e.g. silicon, when characterizing platinum particles or aggregates of $\mathrm{H}_{2} \mathrm{~B} 1-250$.

\section{Oxidation of M ethyl $\alpha$-D-G lucopyranoside}

The oxidation reaction of methyl $\alpha$-D-glucopyranoside to 1-o-methyl $\alpha$-D-glucuronate is shown in Fig. 7. Figure 8 shows the initial specific consumption rate, $R_{\mathrm{w}}^{0}$, as a function of the number of oxidation runs and the number of overnight $\mathrm{N}_{2}$ treatments. During each run the rate decreased due to overoxidation $(16,18)$. R egeneration of the catalyst after $10 \times 10^{3} \mathrm{~s}$ reaction by replacing the oxygen flow by nitrogen and hydrogen for $1.8 \times 10^{3} \mathrm{~s}$ and resum- ing the oxygen feed results in the complete recovery of the initial rate in the next oxidation run. Complete recovery was not observed if the catalyst was kept under nitrogen overnight in the reaction solution at $323 \mathrm{~K}$ for $50 \times 10^{3} \mathrm{~s}$ prior to the regeneration. This is clear in Fig. 8 from the decrease of the initial rate with an increase of the number of overnight $\mathrm{N}_{2}$ treatments.

Extension of the oxidation time to $40 \times 10^{3} \mathrm{~s}$ during oxidation run 2 after two overnight $\mathrm{N}_{2}$ treatments did not result in a change of the initial rate after regeneration. Consequently it is concluded that deactivation during oxidation caused by platinum particle growth and site coverage can be neglected and that the deactivation as a result of two overnight $\mathrm{N}_{2}$ treatments is not recovered.

Deactivation due to platinum leaching could be neglected. The platinum ion concentration in the reactor solution was measured 11 times during the experiment both at the beginning and the end of an oxidation run. No effect of the run time on the platinum ion concentration was observed. The average platinum ion concentration amounted to $0.6 \pm 0.1 \times 10^{-3} \mathrm{~mol} \mathrm{~m}^{-3}(0.12 \mathrm{ppm})$. This concentration corresponds to a total loss of $1 \%$ of the amount of platinum present. During the oxidation of methyl $\alpha$-D-glucopyranoside Schuurman et al. (16) measured a higher platinum concentration of $10-20 \times 10^{-3} \mathrm{~mol} \mathrm{~m}^{-3}$ (2-4 ppm).

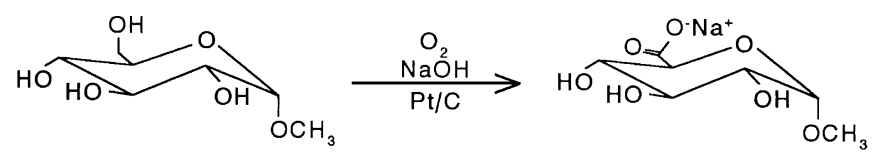

FIG. 7. The oxidation reaction of methyl $\alpha$-D-glucopyranoside to sodium 1-o-methyl glucuronate with molecular oxygen over a platinum catalyst. 
The results of the characterization of three samples which were used for the oxidation of methyl $\alpha$-D-glucopyranoside are listed in Table 1 and denoted by $\mathrm{M} 1, \mathrm{M} 4$, and $\mathrm{M} 7$. The number indicates the number of intermediate regenerations with $\mathrm{N}_{2}$ and $\mathrm{H}_{2}$ for $1.8 \times 10^{3} \mathrm{~s}$. Prior to each experiment the catalyst was reduced at $363 \mathrm{~K}$ in water. The catalyst characterization results after this prereduction are listed in Table 1 as $\mathrm{H}_{2} \mathrm{~L}$.

From Table 1 it can be concluded that the increase of the platinum particle diameter of the catalysts used for the methyl $\alpha$-D-glucopyranoside oxidation is small compared to the fresh catalyst and that no further increase is observed after the prereduction. The fraction exposed, which decreased after prereduction from 0.56 to 0.41 , remained constant for $\mathrm{M} 1$ and $\mathrm{M} 4$ which were not treated overnight, whereas for $M 7$ it decreased further to 0.27 . A t equal platinum particle diameter this decrease must be attributed to site covering, which is caused by the overnight storage in nitrogen atmosphere and corresponds to the decrease of the initial rates in Fig. 8 after each overnight $\mathrm{N}_{2}$ treatment.

From the TE M micrographs of catalysts used for reaction or the pre-reduced sample $\mathrm{H}_{2} \mathrm{~L}$ another form of irreversible deactivation was observed, which was already mentioned for the experiments in which the catalyst was treated in a hydrogen atmosphere at high temperature and high $\mathrm{pH}$. In Fig. 9 the TEM micrograph of catalyst sample M 7 is given. Small platinum aggregates like the ones observed for the aqueous phase hydrogen-treated catalyst $\mathrm{H}_{2} \mathrm{~B} 1-250$ appear.

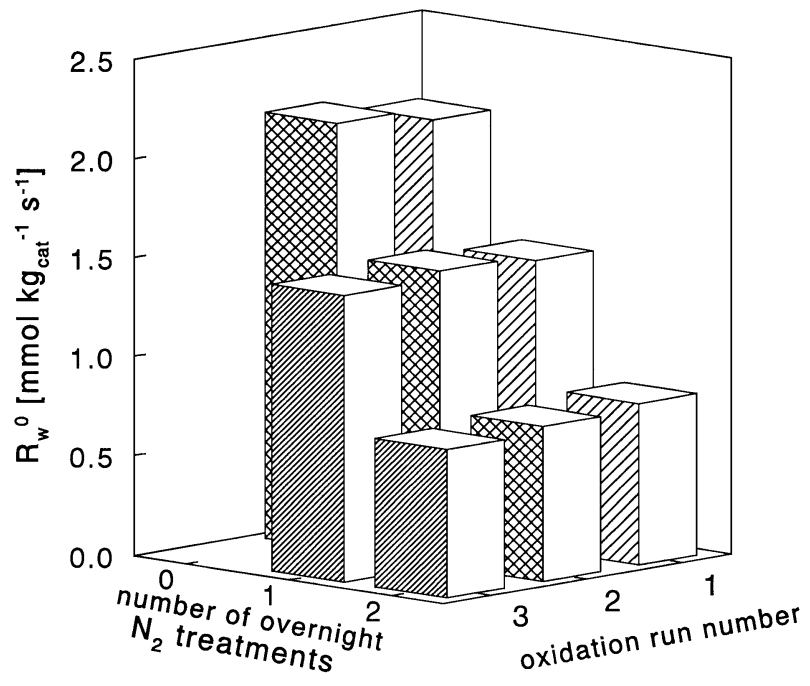

FIG. 8. The initial rate of consumption of sodium hydroxide, $R_{w}^{0}$, for the oxidation of methyl $\alpha$-D-glucopyranoside for eight successive oxidation runs. $B$ efore each oxidation run a regeneration with nitrogen and hydrogen was applied in situ for $1.8 \times 10^{3} \mathrm{~s}$ at $323 \mathrm{~K}$. The overnight $\mathrm{N}_{2}$ treatments were applied by stirring the catalyst for $50 \times 10^{3} \mathrm{~s}$ in the reactor solution in a nitrogen atmosphere prior to the regeneration. Conditions: $\mathrm{C}_{\mathrm{MGP}}=$ $186 \mathrm{~mol} \mathrm{~m}^{-3}, \mathrm{C}_{\mathrm{NaMG}}=6.5 \mathrm{~mol} \mathrm{~m}^{-3}, \mathrm{pH}=9, \mathrm{~T}=323 \mathrm{~K}, \mathrm{p}_{\mathrm{O}_{2}}=10^{5} \mathrm{~Pa}, \mathrm{C}_{\mathrm{cat}}=$ $2 \mathrm{~kg} \mathrm{~m}^{-3}$.

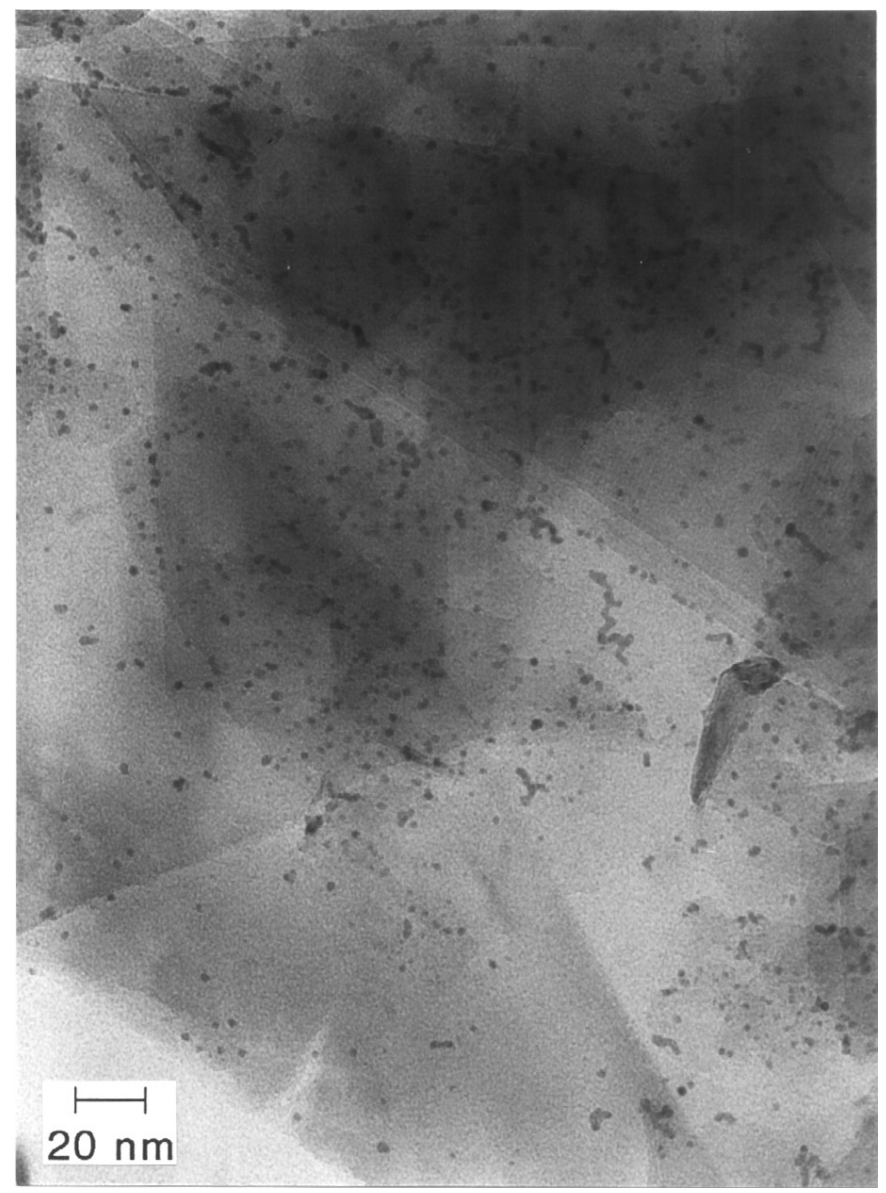

FIG . 9. M icrograph (TE M ) of catalyst sample M 7 after the oxidation reaction of methyl $\alpha$-D-glucopyranoside.

\section{DISCUSSION}

The decrease of the $\mathrm{CO}$ chemisorption capacity upon aqueous phase reduction at high $\mathrm{pH}$ as shown in Fig. 5 is caused by two distinct phenomena. First, platinum particle growth is clearly observed with TE M and XR D asindicated in Table 1 by the $\mathrm{H}_{2} \mathrm{~B}$-samples. Furthermore, the appearance of aggregates of platinum particles is shown in Fig. 6 . Second, site covering is concluded from the fact that the calculated $d_{\mathrm{s}}^{\mathrm{CO}}$ increased relatively more than $d_{\mathrm{s}}^{\mathrm{TEM}}$ and $d_{\mathrm{w}}^{T E M}$. A Iso, site covering is indicated by the increase of the fraction exposed if, subsequent to the reduction experiment, aqueous phase oxidation was applied as indicated in Table 1 by $\mathrm{H}_{2} \mathrm{~B} 2-250 \mathrm{R}$.

For the oxidation reaction of methyl $\alpha$-D-glucopyranoside, site covering, platinum leaching, and particle growth have been shown to take place as a result of prolonged use of the catalyst $(16,18)$. In the present case the extent of deactivation by platinum leaching and particle growth is limited, whereas site covering causes a more extensive decrease of the reaction rate, indicated by the decrease of the $\mathrm{FE}^{\mathrm{CO}}$ of sample M 7 in Table 1. 
U pon gas phase treatment at $773 \mathrm{~K}$, platinum particle growth is limited in a hydrogen and nitrogen atmosphere, as indicated by $\mathrm{H}_{2} \mathrm{G}$ and $\mathrm{N}_{2} \mathrm{G}$ in Table 1 . In an oxygen atmosphere, however, a large increase of the platinum particle diameter was observed as is clear from the $\mathrm{O}_{2} \mathrm{G}$ data in Table 1.

Clearly, the mechanism according to which platinum particle growth and site covering occur strongly depends on the catalyst environment. The gas phase used during the gas and aqueous phase experiments and the $\mathrm{pH}$ in the aqueous phase experiments are two important variables determining the extent of particle growth and site covering.

\section{Platinum Particle G rowth}

The decrease of the $\mathrm{CO}$ chemisorption capacity upon aqueous phase reduction is most predominant at high $\mathrm{pH}$ in a hydrogen atmosphere, as indicated in Fig. 4. The decrease of the $\mathrm{FE}^{\mathrm{CO}}$ in Fig. 5 is partly caused by platinum particle growth as is clearly observed with TE $M$ and X RD and indicated in Table 1 for the $\mathrm{H}_{2} \mathrm{~B}$-samples by the increase of the average platinum particle diameter upon time of treatment. A Iso, from Fig. 2 it appearsthat the platinum particle diameter distributions are skewed toward the larger diameter side with increasing time of treatment. F urthermore, the appearance of aggregates of platinum particles was shown in Fig. 6.

In general, particle growth may occur by surface migration of platinum particles or atoms or by transport of platinum through the liquid phase. Transfer of platinum through the liquid phase is less likely, because under reducing conditions platinum ions that may dissolve are absent. Surface migration of platinum particles and platinum atoms are two distinct mechanisms, which are not mutually exclusive $(27,43-45)$. The first mechanism involves the random migration of particles resulting in collisions with other mobile or fixed particles, followed by their coalescence, which leads to particle growth. The other mechanism involves interparticle migration of atoms between fixed particles via the support surface. The first surface migration mechanism is termed particle migration and the second, which implies the migration of atoms, corresponds to 0 stwald ripening (27).

The observation that the reductive treatment at $\mathrm{pH}=13$ is coupled with the appearance of aggregates of platinum particles favors the particle migration mechanism. In the aggregates shown in Fig. 6, individual particles can be observed, which are at the first stage of their coalescence. It was proposed by Wynblatt and G jostein (43) that platinum particle migration may occur not by simultaneous translational motion of the whole crystallite, but by migration of platinum adatoms on the platinum surface resulting in an eventual transfer of platinum mass from one side of the particle to the other. This may lead to a change of the particle geometry and the formation of aggregates.
B esides the evidence for the particle surface migration mechanism obtained with TEM , other methods to distinguish between particle and adatom surface migration provide indications that the latter plays only a limited role.

First, for two-dimensional 0 stwald ripening an initial increase of the exposed fraction of platinum atoms may be observed, because crystallites release atoms to the support surface (28). In the first part of Fig. 5, however, a rapid decrease of $\mathrm{FE}^{\mathrm{CO}}$ is observed. H ence, this result gives no indication of $O$ stwald ripening, although a small initial increase of the fraction exposed may have been completely compensated by site coverage.

Second, the particle diameter distribution will be different for both particle growth mechanisms. For particle migration and subsequent coalescence a G aussian distribution will become broader and skewed towards the larger particle diameter side. O $\mathrm{n}$ the other hand, 0 stwald ripening will result in a bimodal distribution (46). From Fig. 2 no bimodal distribution can be concluded, although the limited accuracy of the determination of the particle diameter distributions and the impossibility to detect particles below the detection limit of about $0.5 \mathrm{~nm}$ may cause problems in this respect (47).

Third, assuming that particle growth and aggregate formation are caused by particle surface migration, an attempt was made to estimate an average platinum particle migration distance, $x$, after a given time, $t$, and the corresponding particle diffusion coefficient, $D_{p}$. Comparison with literature data may then indicate whether the particle surface migration mechanism is realistic or not.

The above quantities are related by

$$
D_{\mathrm{p}}=\frac{x^{2}}{4 t}
$$

The average migration distance is estimated by calculating the distance from which particles must have migrated toward each other in order to create an aggregate. First, the number of particles which must have formed the aggregate was estimated. For the largest aggregate observed after $250 \times 10^{3}$ s of reduction at $363 \mathrm{~K}$ and $\mathrm{pH}=13$, which is shown in Fig. 6 , it wasestimated that $1.5 \times 10^{4}$ hemispherical particles with $d_{n}=1.45 \mathrm{~nm}$ must have formed the aggregate. $\mathrm{N}$ ext, the number of those hemispherical platinum particles per unit of support surface area was calculated from the BET surface area of $1.02 \times 10^{5} \mathrm{~m}^{2} \mathrm{~kg}_{\text {cat }}^{-1}$ and the platinum content of $3.4 \times 10^{-2} \mathrm{~kg}_{\mathrm{pt}} \mathrm{kg}_{\mathrm{cat}}^{-1}$. From the calculated value of 1 platinum particle per $50 \mathrm{~nm}^{2}$ it follows that $1.5 \times 10^{4}$ platinum particles cover a surface area of $7.5 \times 10^{5} \mathrm{~nm}^{2}$ on the fresh catalyst. If the aggregate is considered as the fixed center of a circle in which all platinum particles have formed the aggregate during the reduction experiment, the radius of that circle is $5 \times 10^{2} \mathrm{~nm}$. If the average particle migration distance, $x$, is equal to the radius of this circle, calculation of the particle diffusion coefficient, $D_{p}$, from $E q$. [6] gives 
$0.2 \times 10^{-18} \mathrm{~m}^{2} \mathrm{~s}^{-1}$. This value is of the same order of magnitude but smaller than that found in gas phase sintering experiments at much higher temperatures. For example, for $2.5 \mathrm{~nm}$ platinum particles on alumina, which were annealed at $873 \mathrm{~K}$ for $5 \mathrm{~h}, \mathrm{a} \mathrm{D}_{\mathrm{p}}$ of $1.5 \times 10^{-18} \mathrm{~m}^{2} \mathrm{~s}^{-1}$ was reported (43). Thus it can be concluded that on the basis of the calculated particle diffusion coefficient the particle surface migration mechanism is realistic.

Clearly, the aqueous phase plays an important role in the particle growth mechanism in a hydrogen atmosphere. Particle migration can occur at a much lower temperature in the liquid phase. Whereas in the gas phase in a hydrogen atmosphere at $773 \mathrm{~K}$ particle growth is limited as indicated in Table 1 by $\mathrm{H}_{2} \mathrm{G}$, the presence of an aqueous phase containing sodium hydroxide accelerates particle migration in a hydrogen atmosphere at $363 \mathrm{~K}$. M oreover, a higher $\mathrm{NaO} \mathrm{H}$ /catalyst ratio results in a larger average particle diameter as indicated by the data for sample $\mathrm{H}_{2} \mathrm{~B} 1-250$ in Table 1, which was treated at a higher $\mathrm{NaO} \mathrm{H}$ /catalyst ratio than $\mathrm{H}_{2} \mathrm{~B} 2-250$. Chu and Ruckenstein (48) explained the increased sintering of platinum particles on a carbon film in gas phase at $773 \mathrm{~K}$ in the presence of water vapor to be a result of a decrease of the particle support interaction, speculating that the particles migrate by floating over the support. In the reduction experiments in aqueous phase the effect of water and hydroxide may be similar. The presence of the aqueous phase may accelerate the destruction of the oxygen-containing surface groups, destroying the platinum support interaction. A Iso, the support surface may be modified by reaction or interaction of hydroxide ions with the acidic support surface groups. B oth effects will stimulate platinum particle surface migration and consequently particle growth. A nother role of $\mathrm{OH}^{-}$might lie in its ability to permit transfer of platinum adatoms from the platinum surface to the graphite support $(28,43)$. In this way the transport of platinum particles on the support may be facilitated via a mechanism in which platinum particle migration occurs by movement of platinum adatoms on the platinum surface, resulting in a eventual transfer of platinum mass from one side of the particle to the other. This mechanism may also explain the formation of platinum aggregates.

D uring the oxidation of methyl $\alpha$-D-glucopyranoside, particle growth is small and occurs only during the prereduction, which was performed in water at $363 \mathrm{~K}$ in a hydrogen atmosphere. The platinum particle diameter measured with TEM or XRD for M 1, M 4, and M 7 in Table 1 shows a small increase compared to the fresh catalyst and no further increase is observed after the prereduction, indicated by sample $\mathrm{H}_{2} \mathrm{~L}$. A Iso, small platinum aggregates are observed for the samples M 1, M 4, and M 7 used for the oxidation reaction and the pre-reduced sample $\mathrm{H}_{2} \mathrm{~L}$ as shown in the TEM micrograph in Fig. 9 for sample M 7. The near absence of particle growth under oxidizing conditions can be correlated with the results of Fig. 8, where after a nor- mal regeneration procedure of $1.8 \times 10^{3} \mathrm{~s}$ the initial rate is completely restored. H ence, as particle growth takes place mainly under reducing conditions and platinum aggregates are observed, the mechanism for particle growth consists mainly of platinum particle migration, as was the case during the hydrogen treatment at $\mathrm{pH}=13$ and $363 \mathrm{~K}$.

Platinum particle growth via a platinum particle migration mechanism also takes place upon gas phase oxidation at $773 \mathrm{~K}$. A large increase of the platinum particle diameter is observed after treatment in an oxygen atmosphere at $773 \mathrm{~K}$, whereas in a hydrogen or nitrogen atmosphere only a small increase is observed, as indicated in Table 1. B ett et al. (28) demonstrated that platinum supported on activated carbon required temperatures in excess of $873 \mathrm{~K}$ to bring about particle growth in a hydrogen and nitrogen atmosphere. Prado-Burguete et al. (49) showed that the oxygen-containing surface groups on the carbon support hamper the platinum particle growth in a hydrogen atmosphere at $773 \mathrm{~K}$. In an oxygen atmosphere, however, platinum-catalyzed carbon burnoff (31) destroys the support together with the anchorage sites, causing platinum particle mobility and particle growth upon collision and coalescence of two particles.

From the gas and aqueous phase experiments it can be concluded that platinum particle growth can be attributed to the destruction of the strong interaction of the platinum particle with the graphite support. The oxygen-containing surface groups of the graphite support, which are responsible for this interaction, are able to inhibit platinum particle growth under mild conditions, e.g. those during the aqueous phase selective oxidation reaction. During hydrogen treatment in liquid phase, especially at high $\mathrm{pH}$ and high temperature, and during oxygen treatment in gas phase at $773 \mathrm{~K}$, these surface groups are destroyed. This causes platinum particle mobility and via collision and coalescence there is particle growth.

It is interesting to compare the $\mathrm{CO}$ chemisorption data for small and large particles with the TEM data, without considering the data which are affected by site coverage. For the fresh catalyst the adsorption stoichiometry, calculated as $d_{\mathrm{s}}^{\mathrm{TEM}} / d_{\mathrm{s}}^{\mathrm{CO}}$, is 0.73 . This value is in good agreement with literature data of Freel (42), who reported 0.85 for platinum on silica catalysts above a fraction exposed of 0.25 , and $R$ odriguez-R einoso et al. (41), who reported 0.62 for activated-carbon-supported platinum catalysts, also for $\mathrm{FE}>0.25$. For larger particles the difference between $d_{\mathrm{s}}^{\mathrm{TEM}}$ and $d_{\mathrm{s}}^{\mathrm{CO}}$ or $d_{\mathrm{w}}^{\text {TEM }}$ and $d_{\mathrm{w}}^{\mathrm{XRD}}$ is smaller than for the fresh catalyst, as indicated in Table 1 for $\mathrm{H}_{2} \mathrm{G}, \mathrm{N}_{2} \mathrm{G}$, and $\mathrm{O}_{2} \mathrm{G}$. A fter the gas phase hydrogen treatment $d_{S}^{\mathrm{TEM}}$ is even larger than $d_{\mathrm{s}}^{\mathrm{CO}}$. Consequently, the $\mathrm{CO}$ adsorption stoichiometry reaches unity for larger particles. $\mathrm{R}$ odriguez-R einoso et al. (41) reported the same effect and proposed two explanations. First, electron transfer from the support toward platinum, which is more pronounced for smaller particles, 
would facilitate bridge-bonded $\mathrm{CO}$. Second, for small particles the fraction of platinum atoms at edges will be greater (50), favoring bridge-bonded $\mathrm{CO}$. A $\mathrm{n}$ increase of the fraction of bridge-bonded CO compared to the fraction of linear-bonded $\mathrm{CO}$ implies that for small particles the $\mathrm{CO}$ adsorption stoichiometry is smaller.

\section{Site Covering}

Site covering was observed to take place during the aqueous phase treatment at $\mathrm{pH}=13$ and $363 \mathrm{~K}$. It is indicated by the increase of the $\mathrm{CO}$ chemisorption capacity of sample $\mathrm{H}_{2}$ B 2-250 after four oxidation-reduction cycles. The fraction exposed recovered to 0.25 as indicated by sample $\mathrm{H}_{2} \mathrm{~B} 2-250 \mathrm{R}$ in Table 1. It has been reported by Vleeming et al. (18) that the decrease of the fraction exposed upon hydrogen treatment at $\mathrm{pH}=13$ could also be partly recovered by potential cycling of the catalyst in an electrochemical setup and by heating in oxygen at $473 \mathrm{~K}$. A nother indication for site covering is that the $d_{\mathrm{s}}^{\mathrm{CO}}$ increased from $2.3 \mathrm{~nm}$ to $14 \mathrm{~nm}$, whereas the increase of the average platinum particle diameter measured with TEM and XRD is much smaller. I $n$ other words, the application of $E \mathrm{q}$. [5], converting the FE ${ }^{\mathrm{CO}}$ to the $d_{\mathrm{s}}^{\mathrm{CO}}$, is actually not allowed in this case, because platinum surface atoms, which are covered, are not available for $\mathrm{CO}$ chemisorption.

The selective oxidation reaction of methyl $\alpha$-D-glucopyranoside is only accompanied by site covering during the prereduction and the overnight stay of the catalyst in the reaction solution under nitrogen. A s a result of the prereduction the fraction exposed decreases from 0.56 for the fresh catalyst to 0.41 for $\mathrm{H}_{2} \mathrm{~L}$ as given in Table 1 . A pplying the regeneration procedure for a relatively short time, a small or even no effect on the rate after regeneration is observed, but maintaining the catalyst overnight under reducing conditions clearly causes a decrease of the initial rate, as indicated in Fig. 8, and a decrease of the fraction exposed, as measured with $\mathrm{CO}$ chemisorption. The fraction exposed decreases from 0.41 for the catalyst prior to the first oxidation run to 0.27 for the catalyst after the last oxidation run (Table 1, M 7). This decrease constitutes the main reason for the decrease of the initial rate in Fig. 8 with increasing number of overnight $\mathrm{N}_{2}$ treatments.

Site covering during the overnight stay of the catalyst in the reaction solution can be caused by the presence of organic side products from the methyl $\alpha$-D-glucopyranoside oxidation. Site covering as a result of the aqueous phase reduction at $\mathrm{pH}=13$ or the prereduction in water at $363 \mathrm{~K}$ must however be caused by products originating from the graphite support. It is assumed that as a result of the destruction of the oxygen-containing surface groups under reducing conditions, which caused platinum particle mobility and particle growth, products are formed which may cause covering of sites. The aqueous phase and the presence of sodium hydroxide in particular play an important role in this respect, because gas phase reduction only has a limited effect on the $\mathrm{CO}$ adsorption capacity. Furthermore, during aqueous phase reduction an increase of the $\mathrm{NaO} \mathrm{H}$ /catalyst ratio results in a larger decrease of the $F E{ }^{C O}$.

\section{CONCLUSIONS}

The extent of modifications of graphite-supported platinum catalysts due to particle growth and covering of metal sites strongly depends on the catalyst environment. Whereas in gas phase oxidation at $773 \mathrm{~K}$ platinum particle growth is largely due to sintering caused by extensive carbon burnoff of the graphite support, in the aqueous phase particle growth is limited during treatment in an oxygen atmosphere. In a nitrogen or hydrogen atmosphere at $773 \mathrm{~K}$ the increase of the particle diameter is small. $\mathrm{H}$ owever, aqueous phase reduction, especially at high $\mathrm{pH}$ and temperature, is responsible for the reduction of the oxygen-containing support surface groups, destroying the platinum anchorage sites. This enables platinum particle surface migration, which leads to the formation of platinum aggregates, particle growth, and site covering with products originating from the graphite support. The decrease of the initial rate for the oxidation of methyl $\alpha$-D-glucopyranoside after reductive regeneration can be ascribed to covering of sites by side products or products originating from the graphite support under prolonged reducing conditions.

\section{APPE NDIX: NOTATION}

Roman Symbols

\begin{tabular}{|c|c|c|}
\hline$b$ & Instrumental line broadening & radians \\
\hline$C$ & Concentration & $\mathrm{mol} \mathrm{m}^{-3}$ \\
\hline$C_{\text {cat }}$ & Catalyst concentration & $\mathrm{kg} \mathrm{m}^{-3}$ \\
\hline$D$ & D iffusion coefficient & $\mathrm{m}^{2} \mathrm{~s}^{-1}$ \\
\hline$d$ & D iameter & $\mathrm{m}$ \\
\hline $\mathrm{FE}$ & Fraction exposed & $\mathrm{mol} \mathrm{Pt}_{\mathrm{s}}(\mathrm{mol} \mathrm{Pt})^{-1}$ \\
\hline $\mathrm{n}$ & Number of particles & \\
\hline$n_{i}$ & $\begin{array}{l}\text { N umber of particles with } \\
\text { diameter } \mathrm{i}\end{array}$ & \\
\hline$p$ & Pressure & $\mathrm{Pa}$ \\
\hline$R_{\mathrm{w}}^{0}$ & $\begin{array}{l}\text { Initial specific consumption } \\
\text { rate }\end{array}$ & $\mathrm{mol} \mathrm{kg} \mathrm{cat}_{\text {cat }}^{-1} \mathrm{~s}^{-1}$ \\
\hline$T$ & Temperature & K \\
\hline 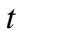 & Time & $\mathrm{S}$ \\
\hline$x$ & A verage migration distance & $\mathrm{m}$ \\
\hline
\end{tabular}

G reek Symbols

$\beta_{1 / 2} \quad$ linewidth at half maximum

radians

$\theta \quad$ B ragg angle of incidence

$\lambda$ wavelength

degrees

$\mathrm{nm}$

$\sigma \quad$ standard deviation 


\section{Subscripts}

$\begin{array}{ll}\text { ads } & \text { A dsorbed } \\ \text { cat } & \text { Catalyst } \\ i & \text { of ith class } \\ \text { M G P } & \text { M ethyl } \alpha \text {-D-glucopyranoside } \\ \text { N aM G } & \text { Sodium 1-o-methyl } \alpha \text {-D-glucuronate } \\ \mathrm{n} & \text { N umber averaged } \\ \mathrm{O} 2 & \text { Oxygen } \\ \mathrm{p} & \text { Particle } \\ \mathrm{S} & \text { Surface } \\ \mathrm{s} & \text { Surface area averaged } \\ \mathrm{w} & \text { Weight averaged }\end{array}$

Superscripts

$\begin{array}{ll}\text { CO } & \text { CO chemisorption } \\ \text { TEM } & \text { Transmission electron microscopy } \\ \text { XRD } & \text { X-ray diffraction } \\ \text { chem } & \text { Chemisorption technique }\end{array}$

\section{ACKN OWLE DG MENTS}

Financial support by the D utch M inistry of A griculture, $\mathrm{N}$ ature $\mathrm{M}$ anagement, and Fishery through its special program on carbohydrate oxidation, Project 70103, and financial support by the E uropean Community through its E uroxycat program are gratefully acknowledged.

\section{REFERENCES}

1. Heyns, K ., and Paulsen, H., A dv. Carbohydr. Chem. 17, 169 (1962).

2. Röper, $H$., in "Carbohydrates as Raw Materials" (F. W. Lichtenthaler, E d.), p. 267. V CH, Weinheim, 1991.

3. Van Bekkum, H., in "Carbohydrates as Raw Materials" (F. W. Lichtenthaler, E d.), p. 289. V CH, Weinheim, 1991.

4. M allat, T., and B aiker, A ., Catal. Today 19, 247 (1994).

5. K han, M. I. A ., M iwa, Y., M orita, S., and Okado, J., Chem. Pharm. B ull. 31, 1141 (1983).

6. K han, M. I. A ., M iwa, Y., M orita, S., and Okado, J., Chem. Pharm. Bull. 31, 1827 (1983).

7. Goodenough, J. B., H amnett, A., Kennedy, B. J., and Weeks, S. A., Electrochim. A cta 32, 1233 (1987).

8. H ronec, M., Cvengrosova, Z., Tuleja, J., and I lavsky, J., in " N ew D evelopments in Selective O xidation" (G. Centi and F. Trifirò, E ds.), Studies in Surface Science and Catalysis, Vol. 55, p. 169. E Isevier, A msterdam, 1990.

9. K imura, H., Kimura, A ., Kokubo, I., Wakisaka, T., and M itsuda, Y., A ppl. Catal. A: General 95, 143 (1993).

10. M allat, T., B odnar, Z ., B rönnimann, C., and B aiker, A ., in "Catalyst Deactivation 1994" (B. Delmon and G. F. Froment, E ds.), Studies in Surface Science and Catalysis, Vol. 88, p. 385. Elsevier, A msterdam, 1994.

11. N icoletti, J. W., and Whitesides, G. M., J. Phys. Chem. 93, 759 (1989).

12. M allat, T., Baiker, A ., and B otz, L., A ppl. Catal. A : G eneral 86, 147 (1992).

13. Dirkx, J. M. H., and van der B aan, H. S., J. Catal. 67, 1 (1981).

14. Dirkx, J. M. H., and van der B aan, H. S., J. Catal. 67, 14 (1981).

15. Dijkgraaf, P. J. M ., D uisters, H. A . M., Kuster, B. F. M ., and van der Wiele, K., J. Catal. 112, 337 (1988).

16. Schuurman, Y., K uster, B. F. M ., van der Wiele, K ., and M arin, G. B., A ppl. Catal. A : G eneral 89, 47 (1992).

17. De Bruijn, F. A., Marin, G. B., Niemantsverdriet, J. W., Visscher, W. H. M., and van Veen, J. A . R., Surf. Interface A nal. 19, 537 (1992).
18. V leeming, J. H., D e Bruijn, F. A ., Kuster, B. F. M ., and M arin, G. B., in "C atalyst D eactivation 1994" (B. D elmon and G. F. Froment, E ds.), Studies in Surface Science and Catalysis, Vol. 88, p. 467. Elsevier, A msterdam, 1994.

19. Brönnimann, C., Bodnar, Z., H ug, P., M allat, T., and B aiker, A., J. Catal. 150, 199 (1994).

20. Van den Tillaart, J. A . A ., Kuster, B. F. M ., and M arin, G. B., in "CataIytic Selective Oxidation" (S. T. O yama and J. W. H ightower, E ds.), A CS Symposium Series, Vol. 523, p. 299. A CS, Washington D. C., 1993.

21. Peukert, M., Coenen, F. P., and Bonzel, H. P., Electrochim. A cta 29, 1305 (1984).

22. A bbadi, A ., and van B ekkum, H., J. M ol. Catal. A : Chemical 97, 111 (1995).

23. Smits, P. C. C., Kuster, B. F. M ., van der Wiele, K ., and van der Baan, H. S., A ppl. Catal. 33, 83 (1987).

24. Parsons, R ., and VanderN oot, T., J. E lectroanal. Chem. 257, 9 (1988).

25. B ae, I. T., Xing, X., L iu, C. C., and Y eager, E ., J. E lectroanal. Chem. 284, 335 (1990).

26. Pérez, J. M ., M uñoz, E., M orallón, E ., Cases, F., V ásquez, J. L., and A ldaz, A ., J. E lectroanal. Chem. 368, 285 (1994).

27. R oss, P. N., in "C atalyst D eactivation" (E . E . Peterson and A . T. B ell, E ds.), Chemical Industries Series, Vol. 30, p. 165. D ekker, N ew York, 1987.

28. B ett, J. A . S., K inoshita, K., and Stonehart, P., J. Catal. 41, 124 (1976).

29. Connolly, J. F., Flannery, R. J., and M eyers, B. L., J. E lectrochem. Soc. 114, 241 (1967).

30. Richard, D., and Gallezot, P., in "Preparation of Catalysts IV" (B. Delmon, P. G range, P. A . Jacobs, and G. Poncelet, E ds.), Studies in Surface Science and Catalysis, Vol. 31, p. 71. E Isevier, A msterdam, 1987.

31. M CK ee, D. W., in "Chemistry and Physics of Carbon" (P. L. Walker and P. A . Thrower, E ds.), Vol. 16, p. 1. D ekker, N ew York, 1981.

32. A yres, C. H., and M eyer, A. S., A nal. Chem. 23, 299 (1951).

33. Charlot, $C$., "L es M éthodes de la Chimie A nalytique." M asson, Paris, 1961.

34. Lemaître, J. L., M enon, P. G., and D elannay, F., in "Characterization of $\mathrm{H}$ eterogeneous $\mathrm{C}$ atalysts" ( $\mathrm{F}$. D elannay, $\mathrm{E}$ ds.), Chemical I ndustries Series, Vol. 15, p. 299. D ekker, N ew Y ork, 1984.

35. G allezot, P., in "C atalysis: Science and Technology" (J. R. A nderson and M. B oudart, E ds.), Vol. 5, p. 221. Springer, B erlin, 1984.

36. Sashital, S. R ., Cohen, J. B., B urwell, R. L., and B utt, J. B., J. Catal. 50, 479 (1977).

37. B ergeret, G., Gallezot, P., and Imelik, B., J. Phys. Chem. 85, 411 (1981).

38. Scholten, J. J. F., Pijpers, A . P., and H ustings, A . M . L ., Catal. R ev.-Sci. Eng. 27, 151 (1985).

39. Scardi, P., and A ntonucci, P. L., J. M ater. Res. 8, 1829 (1993).

40. K lug, H. P., and A lexander, L. E., "X -R ay D iffraction Procedures for Polycrystalline and A morphous M aterials," p. 618. Wiley, N ew York, 1974.

41. R odríguez-R einoso, F., R odríguez-R amos, I., M oreno-Castilla, C., G uerrero-R uiz, A ., and L ópez-G onzález, J. D., J. Catal. 99, 171 (1986).

42. Freel, J., J. Catal. 25, 149 (1972).

43. Wynblatt, P., and G jostein, N. A ., Prog. Solid State Chem. 9, 21 (1975).

44. E hrburger, P., A dv. Colloid I nterface Sci. 21, 275 (1984).

45. R uckenstein, E ., and Sushumna, I , in "H ydrogen E ffects in Catalysts" (Z. Paál and P. G. M enon, E ds.), Chemical Industries Series, Vol. 31, p. 259. Dekker, New York, 1988.

46. Baker, R. T. K ., in "Catalyst D eactivation 1991" (C. H. B artholomew and J. B. Butt, E ds.), p. 1. E Isevier, A msterdam, 1991.

47. Flynn, P. C., Wanke, S. E ., and Turner, P. S., J. Catal. 33, 233 (1974).

48. Chu, Y. F., and R uckenstein, E., Surf. Sci. 67, 517 (1977).

49. Prado-B urguete, C., L inares-Solano, A ., R odríguez-R einoso, F., and Salinas-M artínez de L ecea, C., J. Catal. 115, 98 (1989).

50. Van H ardeveld, R ., and H artog, F., Surf. Sci. 15, 189 (1969). 